\title{
Ironworking technology and social complexity in rural communities in the early medieval Basque Country
}

\author{
David Larreina-Garcia $^{1, *} \&$ Juan Antonio Quirós Castillo ${ }^{1}$
}

The Basquesmith project aims to illuminate the cycle of iron production and consumption by early medieval rural farming communities in the Alava province, Basque Country, northern Spain.

\section{Introduction}

A recent upturn in archaeological research on European rural medieval settlements has expanded our understanding of early medieval $(-A D$ 400-1000) peasantry. Traditionally described as stagnated and practising a subsistence economy, the peasantry is now understood to have been a dynamic and complex driver of social change (e.g. Devroey 2006; Rollason 2012). The general lack of excavated iron implements for everyday use, however, contributes to the idea that the lower classes rarely used metals, as "iron objects were expensive items" (Jaritz 1995: 180); its use was mostly restricted to elites, who typically consumed iron as weapons and armour. It is also assumed that the fall of the Roman Empire negatively affected the iron industry across Europe, impinging on production and distribution, and ultimately redirecting the production of iron objects towards exclusive consumption by elites; iron simply became too expensive for most of the population (e.g. Fossier 2000).

Investigations by the University of the Basque Country (UPV-EHU), focusing on agrarian archaeology in the province of Álava (northern Spain), have, however, revealed the constant and relatively abundant presence of diverse iron tools on several medieval rural farming settlements dating to the sixth to twelfth centuries (Figure 1). Furthermore, a large number of small, contemporaneous iron-making workshops-typically equipped with a single shaft furnace- have been located in the Atlantic area of the Basque Country. These two conditions provide an unusual opportunity to study local early medieval iron production.

\section{The Basquesmith project}

'Basquesmith' (Marie Curie action 746058, H2020-MSCA-IF-2016) is a two-year, crossdisciplinary research project, which aims to investigate common tools used by lower-class

1 Research Group in Heritage and Cultural Landscapes, University of the Basque Country UPV-EHU, Francisco Tomas y Valiente, 01006 Vitoria-Gasteiz, Spain

Author for correspondence (Email: david.larreina@ehu.eus)

(C) Antiquity Publications Ltd, 2018

ANTIQUITY 92 364, e9 (2018): 1-5

https://doi.org/10.15184/aqy.2018.149 


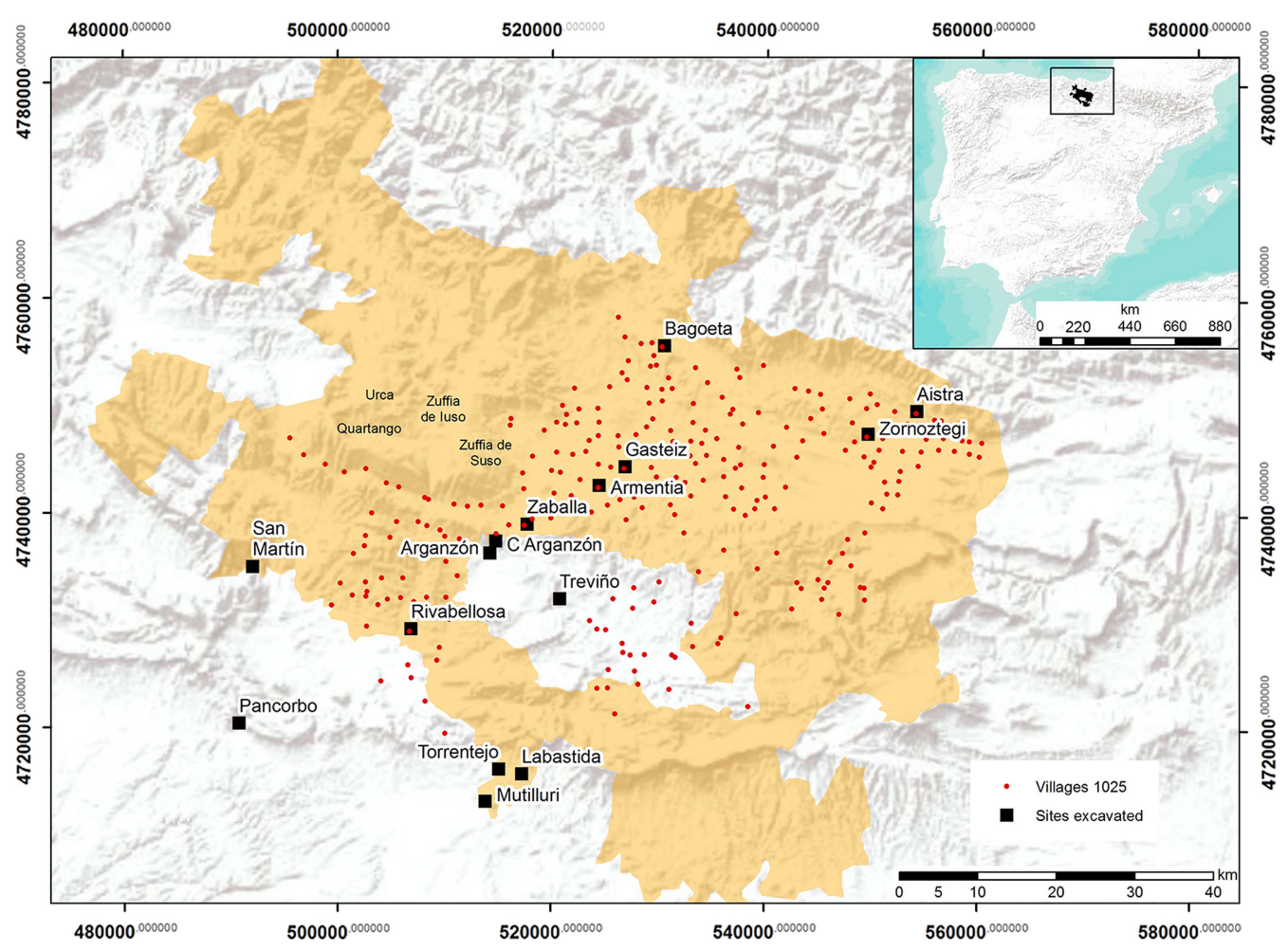

Figure 1. Location of Álava and the excavated rural sites. The red dots represent potential settlements mentioned in the Reja de San Millán document, which dates to AD 1025 (figure by Juan Antonio Quirós Castillo).

members of society, to reconstruct the available technologies and to explore iron consumption by the early medieval peasantry. Most studies of early medieval iron metallurgy focus on the technological, artistic and art-historical aspects of artefact production by elites (e.g. Peirce 2002; Goodall 2011). This project aims to explore the engineering parameters behind the production of farming tools and common implements by examining the manufacture of artefacts, such as scissors, horseshoes, sewing needles, ladles or keys, as well as by examining technical materials (e.g. slag) that are rarely found at the farming sites where the artefacts were excavated (Figure 2). The research will include microanalysis of materials by optical microscopy, scanning electron microscopy coupled with wavelengthdispersive spectroscopy, and radiographic studies.

Despite a recent increase in archaeometric studies of early medieval iron and steel artefacts (e.g. Blakelock \& McDonnell 2007), quotidian tools are seriously underrepresented in favour of high-status and exotic items-typically weapons from hoards or cemeteries. In this sense, this project is unique, as it studies a range of rarely examined objects that were excavated from rural settlements.

The project also takes a novel and comprehensive dual approach: it investigates the entire metallurgical process, from raw materials to objects (including smithing, repairing and consumption), while approaching metallurgical technology as part of the myriad of dynamic 

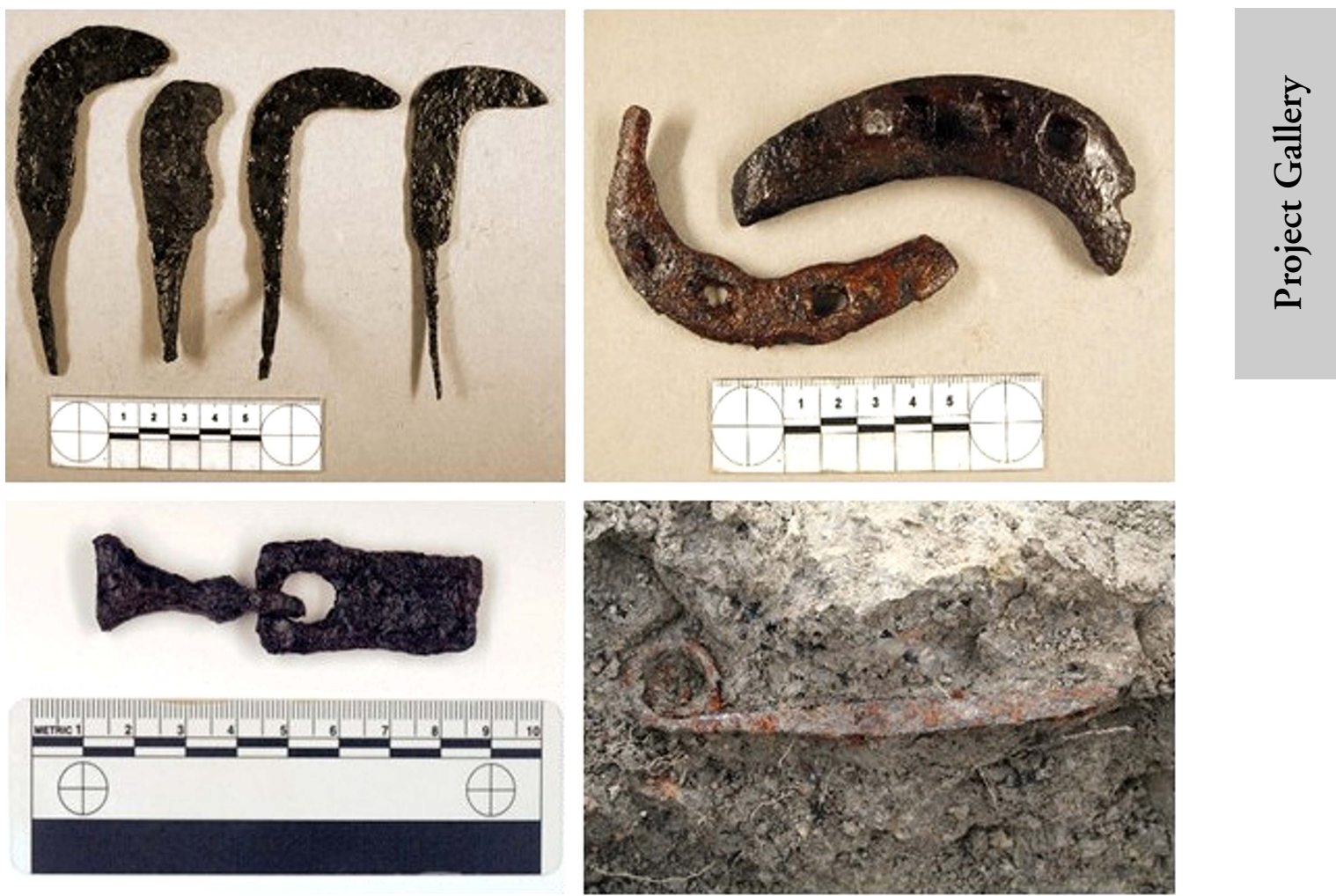

Figure 2. Selection of items analysed so far, including billhooks, horseshoes, a belt buckle with its clasp (conserved after sampling) and a blade from a pair of scissors (revealed during excavation) (figure by the authors).

human activity. This study on the diversity of the archaeometallurgical, archaeological and historical record is anchored in investigating how a specific social stratum utilised metallurgy. To what extent and on what scale were those processes influenced by social contacts? We aim to interpret and reconstruct artefact 'life histories' in order to understand materials and technologies as products and expressions of society and culture, thus enabling a better understanding of past social structures and human-environmental interactions.

This study is important both for understanding the early medieval Basque Country, and because it addresses a wide gap in the research: namely the accessibility of iron to Western European rural communities.

\section{Preliminary results}

Preliminary analyses suggest that most of the assemblage was forged from single pieces of low-carbon iron, without heat-treatment. Instead, the tools were cold-forged to enhance their hardness and durability (Larreina-Garcia \& Quirós Castillo 2018) (Figure 3). Other tools were composite, typically made by welding steel onto an iron back (Figure 4).

Our initial findings suggest that the early medieval peasantry in Álava had access to a wide variety of common, iron-made implements, which were of typically modest quality but

(C) Antiquity Publications Ltd, 2018 


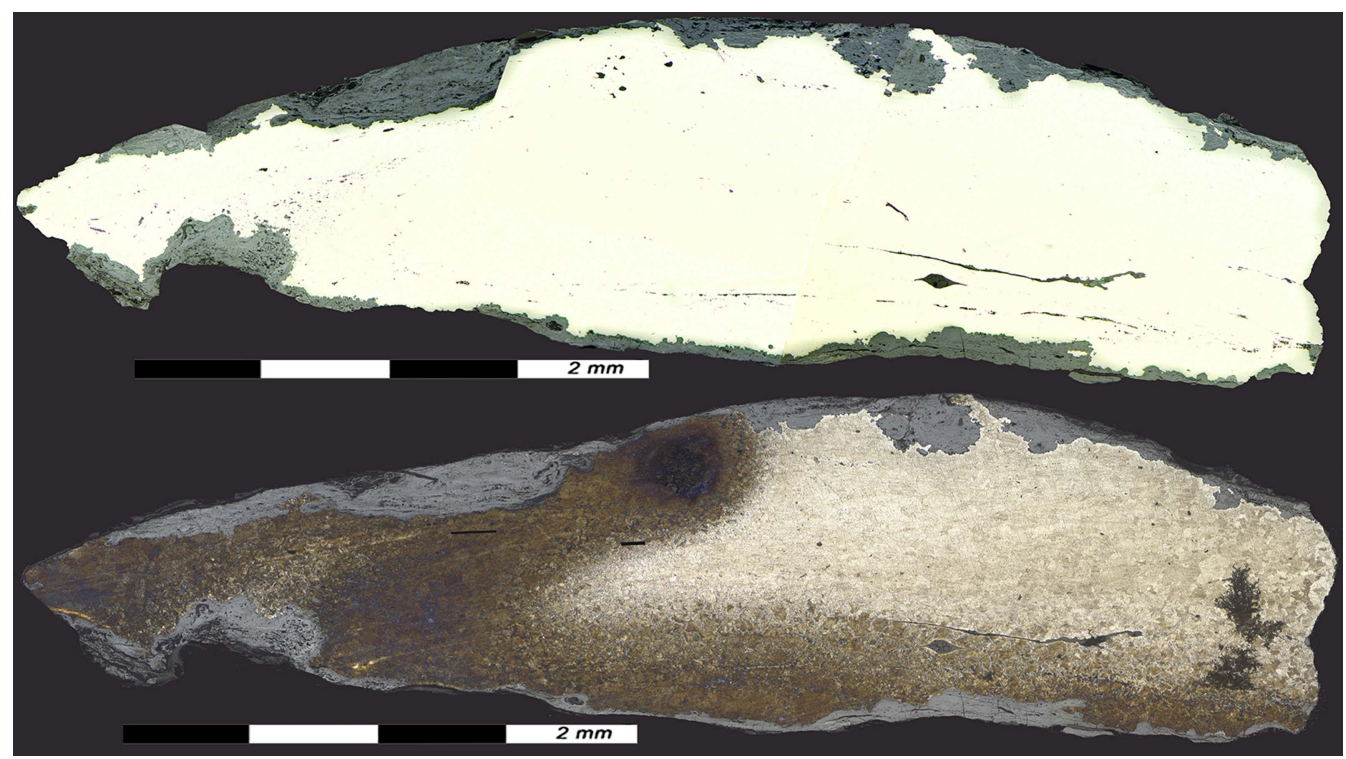

Figure 3. Top) billhook (following conservation), prior to sampling; bottom) macrophotograph showing the etched section of low-carbon iron, with abundant stress lines and stressed grains due to cold working (figure by Paloma López Sebastián and David Larreina-Garcia).
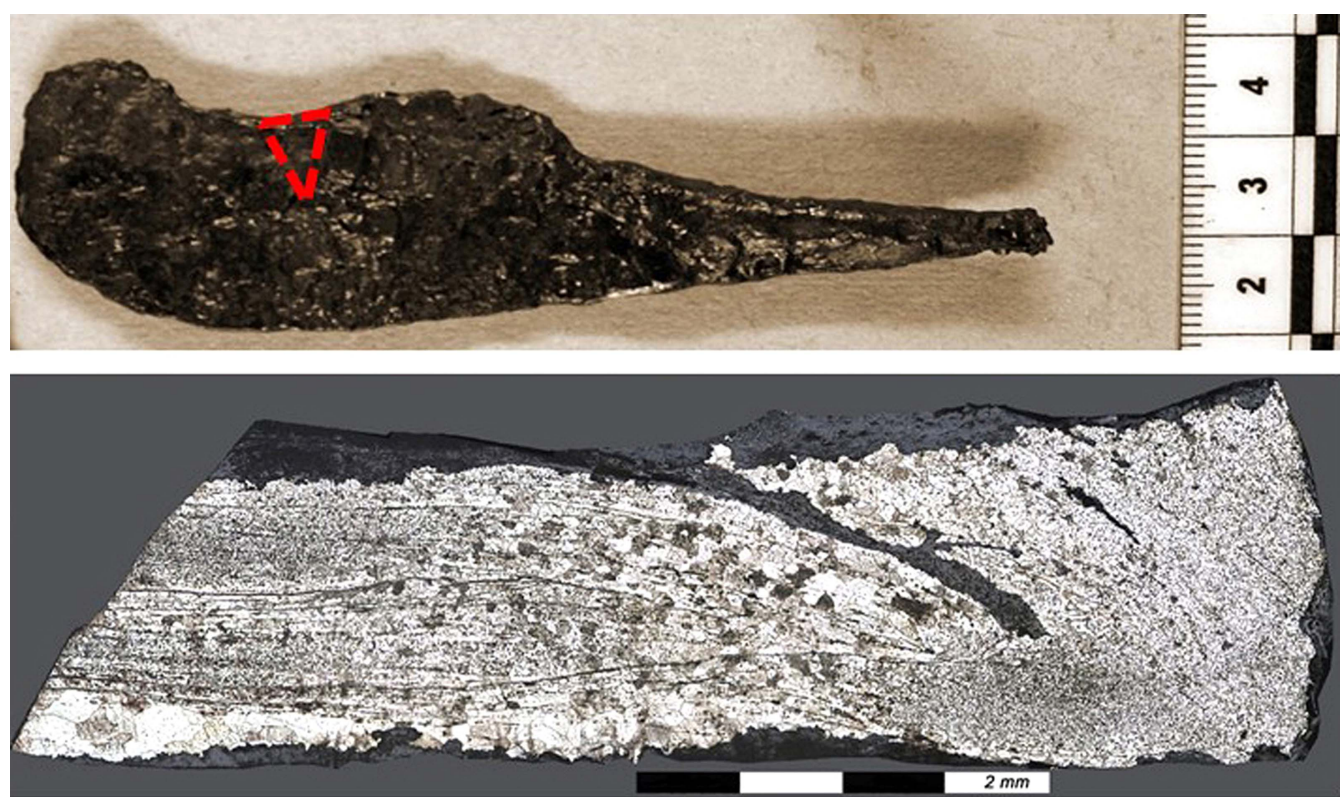

Figure 4. Unetched (top) and etched (bottom) section of scissors (OM, plain polarised light), showing a ferritic core, a steel edge and a line of slag inclusions between them (micrographs by David Larreina-Garcia).

perfectly functional; higher-quality pieces are less frequent. The items were occasionally repaired in rural settlements, but were manufactured elsewhere. The volume of items and

(C) Antiquity Publications Ltd, 2018 
sites suggests the presence of an active iron market, comprising primary producers-probably located in the nearby mountains - and the network of local farming communities consuming these products. Further systematic analyses and archaeological excavations will contribute to a better understanding of the early medieval iron production and consumption cycle in the Basque Country.

\section{References}

Blakelock, E. \& G. McDonnell. 2007. A review of metallographic analyses of early medieval knives. Historical Metallurgy 41: 40-56.

Devroey, J.-P. 2006. Puissants et misérables. Système social et monde paysan dans l'Europe des Francs (VieIXe siècles). Bruxelles: Académie royale de Belgique.

Fossier, R. 2000. Le travail au Moyen Agge. Paris: Hachette.

Goodall, I.H. 2011. Ironwork in medieval Britain: an archaeological study. London: Society for Medieval Archaeology.

JARITZ, G. 1995. Material culture of the peasantry in the Late Middle Ages, in D. Sweeney (ed.)
Agriculture in the Middle Ages: technology, practice and representation: 163-88.

Philadelphia: University of Pennsylvannia Press.

Larreina-Garcia, D. \& J.A. Quirós Castillo. 2018. The metallography of medieval agricultural and quotidian iron utensils from the rural settlement of Zaballa (Basque Country). Archaeometry 2018.

https://doi.org/10.1111/arcm.12387

Peirce, I. 2002. Swords of the Viking Age. Woodbridge: Boydell.

Rollason, D. 2012. Early Medieval Europe 3001050. The birth of Western society. Harlow: Pearson. 